\title{
PROPOSIÇÃO DE METODOLOGIA PARA A ANÁLISE DA EXPANSÃO DA REDE DE GÁS NATURAL NAS CIDADES BRASILEIRAS USANDO INDICADORES URBANOS
}

\author{
Vanessa Meloni Massara \\ Doutora em Energia pelo Instituto de Eletrotécnica e Energia da Universidade de São Paulo- USP \\ Pesquisadora da Escola Politécnica da Universidade de São Paulo - Poli-USP \\ vanessa.massara@gmail.com (Brasil)
}

\section{Miguel Edgar Morales Udaeta}

Doutor em Engenharia da Energia pela Escola Politécnica da Universidade de São Paulo- USP Professor Colaborador da Escola Politécnica da Universidade de São Paulo - Poli-USP udaeta@pea.usp.br (Brasil)

\section{RESUMO}

Neste artigo apresenta-se metodologia para determinação de áreas atraentes para a implantação de gás natural canalizado sob o enfoque do desenvolvimento urbano. $\mathrm{O}$ ponto considerado inovador nesta proposta está baseado na inclusão de parâmetros retirados de planos diretores além dos já conhecidos custo e facilidades tecnológicas. Assim, a modelagem contempla a dinâmica das cidades brasileiras localizadas em regiões metropolitanas, em constante transformação de usos do solo pela intensificação do mercado imobiliário e, até mesmo do zoneamento, transformando áreas subutilizadas em vetores consumidores de energia. Como conclusão, apresenta-se o teste da proposição para 10 distritos da zona leste da capital paulista, evidenciando o importante papel que a dinâmica urbana pode estabelecer no processo decisório para implantação e expansão das redes de infraestrutura.

Palavras-chave: Inovação; Desenvolvimento urbano; Infraestrutura. 


\section{INTRODUÇÃO}

Para que haja condição de implantar a rede de distribuição [1] é necessário que duas situações ocorram. Primeiro que haja gás natural (oferta) e depois, que haja consumo (demanda) que consolide o mercado e justifique o investimento em redes de distribuição. De acordo com a projeção de evolução do consumo de gás natural feita pela ABEGÁS (2008) e avalizada pela Empresa de Pesquisa Energética (EPE), em 2015 serão utilizados diariamente 71,9 milhões de $\mathrm{m}^{3}$ e segundo a EPE, neste prazo a oferta e demanda de gás serão plenamente compatíveis. A oferta para servir à distribuição, está vinculada primeiramente a Bacia de Campos (Rio de Janeiro), ao gasoduto Brasil-Bolívia e a exploração ainda em desenvolvimento, da Bacia de Santos. Acrescenta-se ainda, as descobertas do campo de Manati (Bahia) e do campo de Peroá-Cangoá (Espírito Santo). Como outra opção oriunda da Integração Energética Latino-Americana, surge o campo descoberto no início de 2008 no Peru e por fim, o poço Júpiter, descoberto também em 2008, com projeção de dimensões gigantescas e que poderá levar o Brasil à auto-suficiência na produção de gás natural (BNDES, 2006; GASBRASIL, 2008).

Com as reservas de gás natural, como as da Bacia de Santos (BS400), deverá haver no Brasil uma profunda reflexão por parte de todos aqueles que diretamente ou indiretamente tem uma relação com o desenvolvimento econômico e tecnológico e também com a produção de empregos (Udaeta et al, 2004).

Com essa projeção favorável de oferta futura do gás natural, entre suas várias possibilidades de utilização (demanda), seleciona-se neste trabalho, o enfoque de sua utilização nos usos cotidianos (residências, comércio, prestação de serviços e indústrias), enquanto rede canalizada de distribuição, através da proposta de metodologia que, com base em indicadores urbanos que caracterizam as cidades brasileiras, defina áreas passíveis de expansão do serviço em questão.

\section{METODOLOGIA}

A metodologia baseada em indicadores urbanos tem como objetivo desenvolver procedimentos que permitam analisar e orientar a expansão da rede física de gás natural canalizado dentro de um município através da análise conjunta dos setores de consumo com base na dinâmica

Revista de Administração e Inovação, São Paulo, v. 10, n.2, p. 102-122, abr./jun. 2013. 
urbana que determina a expansão do sistema de rede de gás natural em áreas metropolitanas. A figura 1 resume a abrangência e reflexos da metodologia proposta.

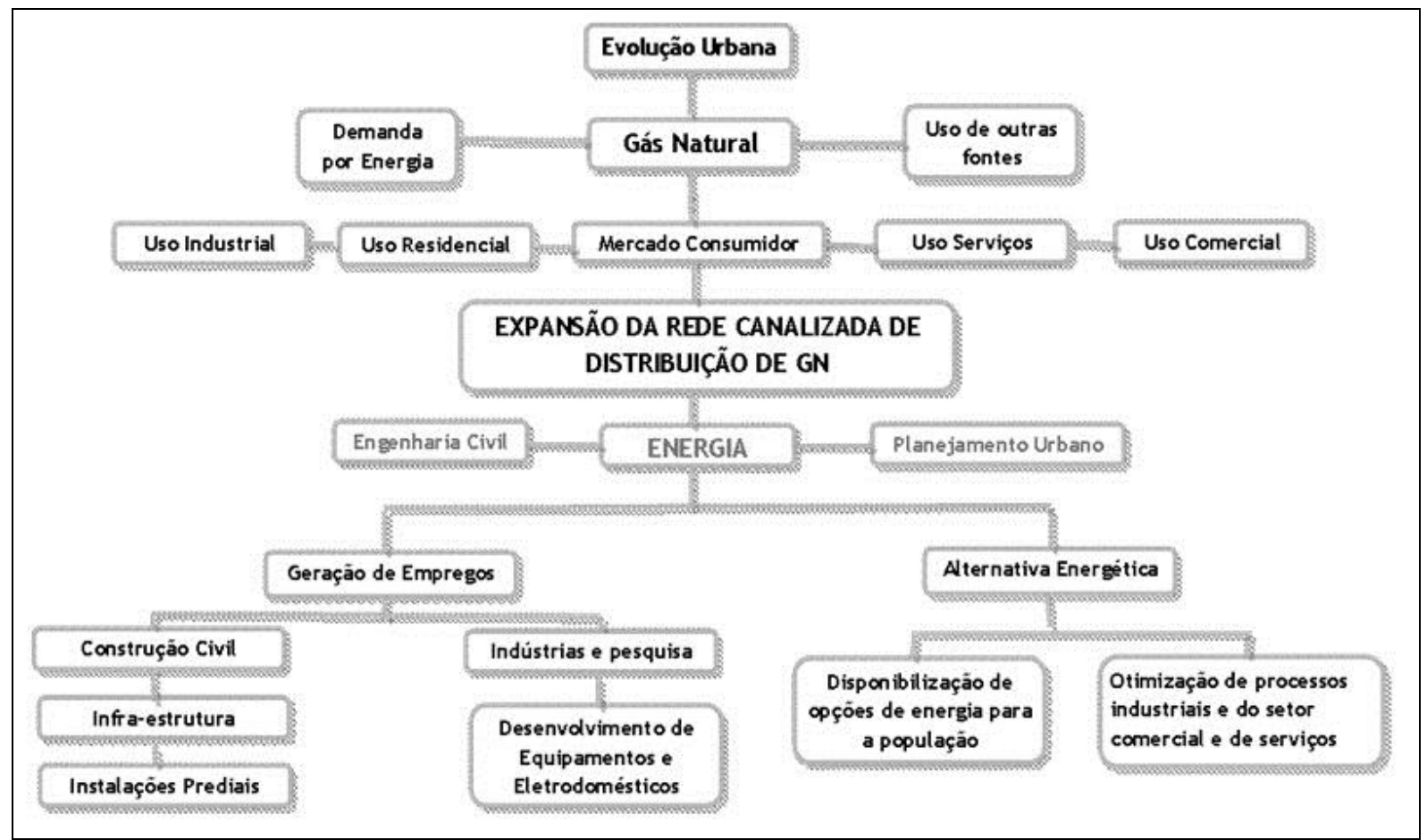

Figura 1 - Abrangência e reflexos da proposta metodológica para a análise de expansão da rede subterrânea de distribuição do gás natural. .

Fonte: própria, 2007.

Na tomada de decisão, para construção e ampliação das redes de infra-estrutura, diferentes fatores devem ser considerados para a priorização do atendimento a áreas que constituirão um mercado consumidor potencial para o serviço em questão (Udaeta, 1997; Massara, 2007; Heideier et al, 2009). Neste trabalho, propõe-se a análise conjunta de aspectos sociais, técnicos e econômicos associados ao processo de ocupação dos grandes centros urbanos, como base para verificação de estimativas de mercado, custos e técnicas mais apropriadas para a ampliação da infra-estrutura de distribuição canalizada de gás natural. Como base ao estudo proposto, sugere-se a criação de um modelo, que integre a compreensão da dinâmica urbana às estratégias de expansão da rede de distribuição de gás, caracterizando as possibilidades de consumo em faixas de atratividade.

O modelo desenvolve-se através da organização de quatro sistemas de informações: aspectos de qualidade de vida, planejamento urbano, projeções de demanda por estratificação em tipos de uso do solo e características da obra civil. Relacionando dados sociais ao consumo estimado por tipo de ocupação do solo às características de ramificação da rede, a metodologia permite classificar cada área 
que compõe uma cidade segundo a viabilidade (atratividade) de implantação da rede de distribuição de gás. Para verificação da coerência metodológica, seleciona-se uma aplicação específica para a questão do mercado paulista.

Como conclusão, apresenta-se o ranking de atratividade a implantação do gás canalizado em distritos da cidade selecionada para teste, através da modelagem baseada na dinâmica urbana, a fim de apontar as possibilidades do gás natural, substituir outras formas de energia final nos usos urbanos (Udaeta et al, 2010), visando à incorporação sustentável dessa infra-estrutura.

A modelagem sistêmica dos fatores envolvidos foi elaborada através das seguintes etapas:

- Consideração de três grupos de interesse:

1. A concessionária do serviço de distribuição, que visa instalar a rede com a melhor técnica;

2. A prefeitura dos municípios, representada por seus departamentos de obras, infraestrutura e planejamento urbano, que rege a inserção das redes em perímetro urbano;

3. A população, que deve futuramente usufruir do serviço instalado, independente de sua renda ou localização (periferias, distritos centrais, etc.)

- Identificação, caracterização e sistematização dos principais fatores intervenientes com base no conceito de dinâmica urbana (tema abordado no próximo item deste artigo);

- Definição das células de estudo conforme a disponibilidade de informações sobre os parâmetros. Partindo da unidade de estudo, os dados vão sendo armazenados conforme o detalhamento desejado pelo usuário do modelo, caminhando para células maiores até chegar à área da cidade (unidade, quarteirão, bairro, distrito, município) criando uma lista que deve ser associada às zonas da cidade (os pontos cardeais). Escolhida uma célula de estudo, esta será o padrão. A mistura de diferentes escalas geográficas não é recomendada. Uma vez criada a lista de células de estudo, esta automaticamente se repete no passo seguinte que corresponde ao preenchimento do banco de dados;

- Sistematização dos parâmetros: consiste no preenchimento de dados sobre os quatro sistemas de informação junto a órgãos públicos, constituindo um banco de dados;

- Hierarquização de parâmetros quantitativos e qualitativos através da atribuição de uma escala de priorização que unifica a dimensão de todos os indicadores avaliados na célula de estudo para que possam ser tratados matematicamente. A escala de hierarquização escolhida é a do método de análise hierárquica, o $A H P$ (Saaty, Vargas, 1980), segundo a associação apresentada na tabela 1.

Revista de Administração e Inovação, São Paulo, v. 10, n.2, p. 102-122, abr./jun. 2013. 
Tabela 1 - Adaptação da escala AHP ao estudo do gás natural

\begin{tabular}{|c|c|c|}
\hline Faixa & Escala Semântica para o Gás Natural & $\begin{array}{c}\text { Escala } \\
\text { AHP }\end{array}$ \\
\hline 1 & Baixa atratividade à implantação da rede & 1 \\
\hline 2 & Baixa a Média atratividade à implantação da rede & 3 \\
\hline 3 & Média atratividade à implantação da rede & 5 \\
\hline 4 & Média a Alta atratividade à implantação da rede & 7 \\
\hline 5 & Alta atratividade à implantação da rede & 9 \\
\hline
\end{tabular}

Fonte: própria, baseado em Saaty, 2006.

*Antes da conversão na escala AHP de 1 a 9, é necessária a unificação de todos os parâmetros na mesma unidade, assim, o modelo deve transformar automaticamente os parâmetros em porcentagem. A seguir, os valores coletados são organizados em 5 faixas. Essa escolha é fundamentada nas informações básicas obtidas na SEADE (2009), no IBGE (2003) e nas prefeituras (SÃO PAULO, 2006) que usam em geral, como divisão de tabelas e mapas 5 agrupamentos, o que facilita a associação da escala semântica para análise da rede de GN aos valores numéricos obtidos em fontes oficiais.

O cálculo dos cinco intervalos numéricos para cada parâmetro é elaborado com base em sua amplitude numérica. Vale ressaltar que cada fator exige um cálculo individual de seus valores extremos para a composição das cinco faixas.

- $\quad$ Aplicação do algoritmo para o cálculo do Índice de Atratividade: a fórmula matemática para determinação do índice compreende a média da soma simples de todos os pesos atribuídos a cada parâmetro por célula de estudo que é baseada no algoritmo de índices oficiais da Prefeitura de São Paulo (EMPLASA, 2008; SÃO PAULO, 2002; 2006).

- Atribuição da escala ordinal às células de estudo conforme o valor calculado dos índices, em ordem decrescente, ou seja, a maior média indica o primeiro lugar e assim sucessivamente, ou seja, elaboração do ranking de atratividade (geral ou por sistemas de informações): corresponde à ordenação classificatória das células de estudo em função do valor obtido no cálculo do Índice de Atratividade.

- Validação do modelo de apoio à tomada de decisão para o planejamento da expansão da rede canalizada de GN através de estudos de caso em municípios do estado de São Paulo e do Brasil (neste caso a capital paulista) e comparação entre o resultado obtido através do modelo e o mapeamento da rede já implantada. 


\section{ANÁLISE DO MERCADO DE GÁS NATURAL ENQUANTO REDE CANALIZADA E A DINÂMICA URBANA}

Como ponto de partida de execução do modelo é utilizado o conceito de dinâmica urbana. Esse conceito é baseado no contínuo 'movimento' e 'transformação' do espaço urbano, conforme estudos de Forrester (1969), em vários âmbitos, incluindo a distribuição espacial de áreas produtivas, residenciais, concentrações populacionais, condições de infra-estruturas e renda, bem como distâncias aos centros mais desenvolvidos (SÃO PAULO, 2002; 2006).

Segundo as possibilidades de atração (e repulsão) à rede de gás natural, geradas pelas vantagens competitivas inseridas no conceito de dinâmica urbana (Massara, 2002; SÃO PAULO, 2006), os fatores que interferem na implantação de infra-estruturas urbanas são vários, desde as possibilidades de consumo pela renda familiar e sofisticação de usos do solo até os custos oriundos das distâncias a servir, bem como, a concentração de prédios, indústrias, hotéis e futuros projetos de intensificação de ocupação de áreas antes representadas por uso residencial horizontal.

A seguir, são descritos os componentes (parâmetros) de cada um dos quatro sistemas de informação que compõem o modelo proposto.

\section{Sistema de Informações 1 - Indicadores de qualidade de vida (IQV)}

A vida econômico-social das metrópoles e nas metrópoles está intimamente associada à conquista de melhores padrões de serviços urbanos. Conforme afirma Meier (1997, p. 9), é a partir da avaliação das redes de infra-estrutura urbana que podemos definir com critério a verdadeira "condição de vida" da população que vive nas áreas urbanizadas.

A extensão, disponibilidade e qualidade dos serviços urbanos básicos como: abastecimento de água, esgotamento sanitário, energia elétrica, coleta de lixo e recolhimento das águas pluviais, indicam a condição de habitabilidade de uma cidade ou metrópole. Outros itens de infraestrutura urbana, tais como pavimentação, transporte público, telefonia, gás canalizado, etc., configuram acréscimos importantes e indispensáveis para a elevação do padrão urbano.

Neste item estão relacionados parâmetros associados à qualidade de vida das cidades que indiretamente interferem na atração à implantação da rede de gás, como déficits de infra-estrutura básica - rede de abastecimento de água, coleta de esgotos, iluminação pública - e fatores que determinam longevidade, melhor situação social e de escolaridade e que indiretamente influenciam na

Revista de Administração e Inovação, São Paulo, v. 10, n.2, p. 102-122, abr./jun. 2013. 
implantação e expansão da rede de gás natural, já que dificilmente para regiões com concentração de usos residenciais, comerciais e de prestação de serviços, será atrativo seu uso se ainda houver déficits de serviços, equipamentos e redes básicas [2].

Este sistema de informações (tabela 2) é representado por valores numéricos, distribuídos em intervalos calculados conforme sua dimensão, expressos pelos três fatores descritos a seguir.

Tabela 2 - Sistema de Informações 1- Indicadores de Qualidade de Vida (QV)

\begin{tabular}{|c|l|c|c|c|}
\hline Parâmetros & Sigla & Unidade & Característica & Função \\
\hline $\begin{array}{c}\text { Índice de Desenvolvimento } \\
\text { Humano }\end{array}$ & IDH & Adimensional & $\begin{array}{c}\text { Finito entre } \\
0 \text { e } 1,0\end{array}$ & $\begin{array}{c}\text { Bons índices atraem rede de } \\
\text { GN (não prioritária) }\end{array}$ \\
\hline Índice de Exclusão Social & IEX & Adimensional & $\begin{array}{c}\text { Finito entre } \\
-1,0 \text { e } 1,0\end{array}$ & $\begin{array}{c}\text { Bons índices atraem a rede } \\
\text { de GN (não prioritária) }\end{array}$ \\
\hline $\begin{array}{c}\text { Atendimento por Rede de } \\
\text { Abastecimento de Água }\end{array}$ & AAA & $\%$ & $\begin{array}{c}\text { Finito entre } 0 \\
\text { e } 100 \%\end{array}$ & Deve preceder a rede de GN \\
\hline $\begin{array}{c}\text { Atendimento por Rede de } \\
\text { Coleta de Esgotos }\end{array}$ & AEC & $\%$ & $\begin{array}{c}\text { Finito entre } 0 \\
\text { e } 100 \%\end{array}$ & Deve preceder a rede de GN \\
\hline $\begin{array}{c}\text { Atendimento por Rede de } \\
\text { Iluminação Pública }\end{array}$ & AIP & $\%$ & $\begin{array}{c}\text { Finito entre } 0 \\
\text { e } 100 \%\end{array}$ & Deve preceder a rede de GN \\
\hline
\end{tabular}

Fonte: própria, 2007.

Esses parâmetros são relacionados à existência de equipamentos sociais (escolas, hospitais e de lazer) e outras redes de infra-estruturas e seu reflexo no bem-estar da população e que indiretamente podem influenciar na implantação de uma rede não prioritária, como é o gás natural se comparada, por exemplo, ao saneamento básico.

\section{Sistema de Informações 2 - Indicadores de planejamento urbano (IPU)}

Os parâmetros listados neste grupo foram retirados do conteúdo básico que deve ter todo Plano Diretor (MINISTÉRIO DAS CIDADES, 2006) [3]. Para a avaliação do potencial de expansão da rede de gás natural considerando "a dinâmica urbana" foram extraídos do P.D. os parâmetros definidos na tabela 3 .

Estes indicadores são trabalhados em uma base de dados composta por parâmetros qualitativos e quantitativos (tabela 3). Para a análise dos valores não numéricos, a estratificação em faixas foi baseada no mapeamento e classificação do Plano Diretor da Cidade de São Paulo (SÃO PAULO, 2002), verificando os tipos de uso atuais e suas perspectivas de expansão (EMBRAESP, 2008), na intenção de elaborar um perfil dos bairros com maior tendência à aglomeração industrial (grande atrativo ao uso do gás natural), seguido dos outros usos, conforme escala de projeção de consumo, descrita a seguir e resumida na tabela 3 .

Revista de Administração e Inovação, São Paulo, v. 10, n.2, p.102-122, abr./jun. 2013. 
Tabela 3 - Sistema de Informações 2 - Indicadores de Planejamento Urbano (PU)

\begin{tabular}{|c|c|c|c|c|}
\hline Parâmetros & Sigla & Unidade & Característica & Função \\
\hline $\begin{array}{c}\text { Uso do Solo } \\
\text { (residencial, comercial, } \\
\text { serviços, industrial) }\end{array}$ & $\begin{array}{l}\text { Usres, Uscom, } \\
\text { Usserv, USind }\end{array}$ & $\%$ & $\begin{array}{l}\text { Finito entre } 0 \mathrm{e} \\
100 \%\end{array}$ & $\begin{array}{c}\text { Caracterizar áreas com maior } \\
\text { potencial de consumo de gás } \\
\text { natural }\end{array}$ \\
\hline Zoneamento & $\mathrm{Z}$ & $\begin{array}{c}\text { Adimensio } \\
\text { nal }\end{array}$ & Qualitativo & $\begin{array}{c}\text { Caracterizar áreas com } \\
\text { expansão do potencial de } \\
\text { consumo de gás natural em } \\
\text { longo prazo (ênfase em uso } \\
\text { do solo) }\end{array}$ \\
\hline $\begin{array}{c}\text { Desenvolvimento } \\
\text { Urbano }\end{array}$ & DU & $\begin{array}{l}\text { Adimensio } \\
\text { nal }\end{array}$ & Qualitativo & $\begin{array}{l}\text { Caracterizar áreas com maior } \\
\text { potencial de consumo de gás } \\
\text { natural em longo prazo } \\
\text { (ênfase em infra-estrutura) }\end{array}$ \\
\hline $\begin{array}{c}\text { Lançamentos } \\
\text { Imobiliários } \\
\text { (residenciais e serviços) }\end{array}$ & LIres, LIserv & Número & Não finito & $\begin{array}{l}\text { Caracterizar áreas com maior } \\
\text { potencial de consumo de gás } \\
\text { natural em curto prazo } \\
\text { (ênfase em uso do solo) }\end{array}$ \\
\hline Taxa de Urbanização & $\mathrm{TU}$ & $\%$ & $\begin{array}{c}\text { Finito entre } 0 \mathrm{e} \\
100 \%\end{array}$ & $\begin{array}{l}\text { Diferenciar áreas onde os } \\
\text { serviços podem ou não ser } \\
\text { em rede }\end{array}$ \\
\hline
\end{tabular}

Fonte: própria, 2007

A escala definida para o uso do solo (SÃO PAULO, 2002) é qualitativa e considera cinco agrupamentos de atração para o gás canalizado, com base na relação tipo de uso versus volume de consumo (Massara, 2007):

-Faixa 1: predominância em ocupação residencial horizontal;

-Faixa 2: predominância em uso misto (comercial e residencial horizontal);

-Faixa 3: predominância em ocupação residencial vertical;

-Faixa 4: predominância em uso misto (comercial, serviços e residencial vertical);

-Faixa 5: predominância em uso misto (residencial e industrial).

O mesmo ocorre para o parâmetro desenvolvimento urbano (SÃO PAULO, 2006):

- Faixa 1: proteção ambiental - limites de áreas públicas e de preservação;

- Faixa 2: urbanização e qualificação urbana - áreas ocupadas predominantemente por população de baixa renda, com grande concentração de loteamentos irregulares e favelas;

- Faixa 3: reestruturação e requalificação - áreas com boa infra-estrutura, mas que passam atualmente por processos de esvaziamento populacional e desocupação dos imóveis; 
- Faixa 4: urbanização em consolidação - áreas com condições de atrair investimentos imobiliários privados em residências e estabelecimentos comerciais e de serviço;

- Faixa 5: urbanização consolidada - áreas formadas por bairros consolidados habitados por população de renda média e alta e com boas condições de urbanização.

\section{Sistema de Informações 3 - Indicadores de Potencial de consumo de gás natural (IPC)}

Em geral, a projeção da demanda por energia sempre é considerada em modelos de prospecção de mercados visando à implantação do serviço em rede (Shively, Ferrare, 2004).

Aqui também, o modelo proposto para a estimativa de consumo de GN utiliza a definição de conversão de outras energias em gás natural, mas também usa a dinâmica urbana como auxiliar para uma projeção mais rápida sem considerar "volumes", definindo o consumo possível utilizando o número de domicílios, estabelecimentos comerciais, de prestação de serviços e instalações industriais, que vão sendo desmembrados por setores produtivos segundo o Cadastro Nacional das Atividades Econômicas (IBGE, 2003). Desta forma, em um primeiro momento, a atividade econômica é agregada em totais de estabelecimentos. Em seguida, exploram-se as divisões setoriais da economia, possibilitando estimativas de consumo através da concentração especial das diversas áreas produtivas na região de estudo, sem considerar porte e consequentemente o consumo de cada energia.

Neste sistema são armazenados dados provenientes de informações do Cadastro Nacional das Atividades Econômicas (CNAE, IBGE, 2003) sobre a ocupação dos bairros combinados a informações da distribuidora de gás que serve a região em estudo (tabela 4). Os parâmetros são todos numéricos, possibilitando a criação das cinco faixas através da simples divisão dos valores obtidos, listadas a seguir.

Tabela 4 - Sistema de Informações 3 - Indicadores de Projeção de Consumo de Gás Natural (PC)

\begin{tabular}{|c|c|c|c|c|}
\hline Parâmetros & Sigla & Unidade & Característica & Função \\
\hline Densidade Demográfica & DD & hab/km² & finito & $\begin{array}{c}\text { Definir demanda por GN } \\
\text { (ênfase na concentração } \\
\text { populacional) }\end{array}$ \\
\hline $\begin{array}{c}\text { Renda Familiar (ou poder de } \\
\text { compra) }\end{array}$ & RF & $\begin{array}{c}\text { R\$ ou salários } \\
\text { mínimos }\end{array}$ & Não Finito & $\begin{array}{c}\text { Definir demanda por GN } \\
\text { (ênfase na possibilidade } \\
\text { financeira de consumir) }\end{array}$ \\
\hline $\begin{array}{c}\text { Estratificação (residencial, } \\
\text { comercial, serviços, } \\
\text { industrial) }\end{array}$ & $\begin{array}{c}\text { Eres, } \\
\text { Ecom, } \\
\text { Eserv, } \\
\text { Eind }\end{array}$ & Adimensional & Não Finito & $\begin{array}{c}\text { Definir demanda por GN } \\
\text { (ênfase de consumo no } \\
\text { setor) }\end{array}$ \\
\hline
\end{tabular}

Fonte: própria, 2007

Para a estratificação em usos do solo e respectivos números de unidades por célula de estudo, a metodologia prevê, um maior detalhamentos. A figura 2 mostra o desmembramento em cinco níveis de Revista de Administração e Inovação, São Paulo, v. 10, n.2, p.102-122, abr./jun. 2013. 
detalhamento, com base da estratificação das atividades econômicas definidas pelo CNAE (IBGE, 2003).

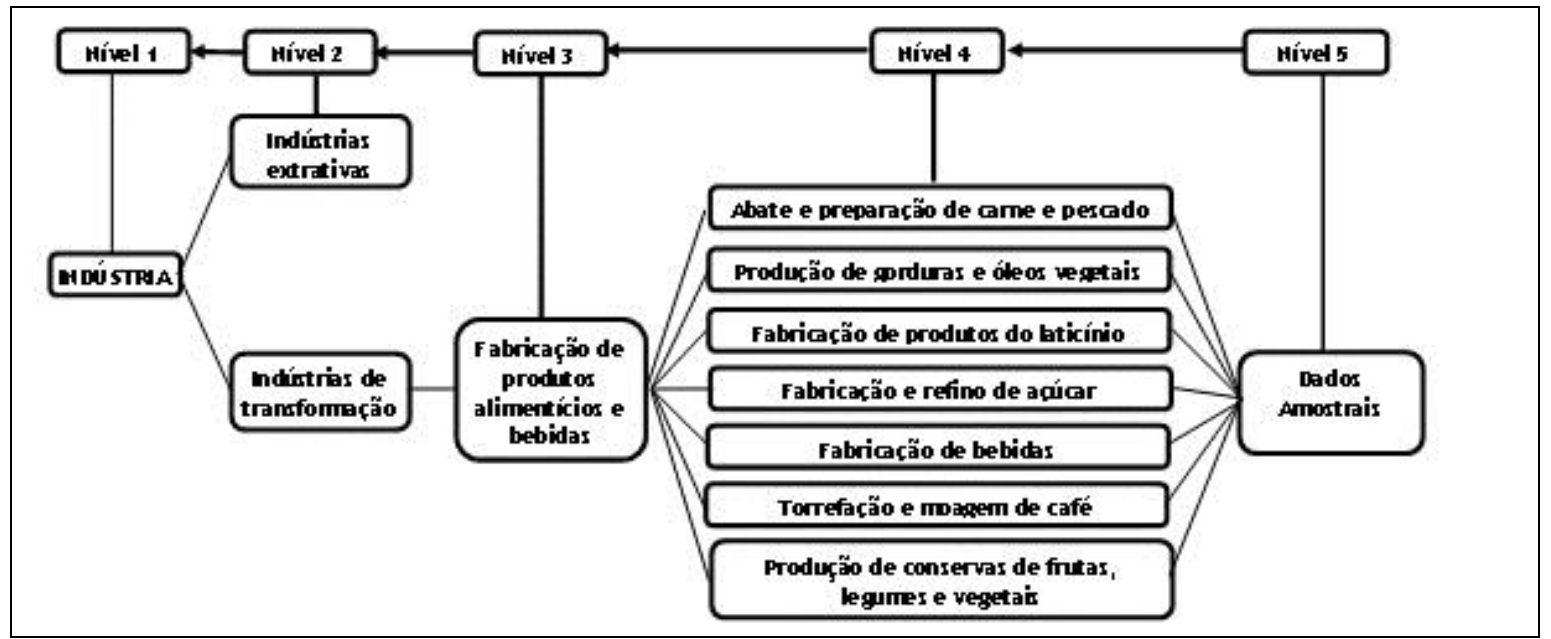

Figura 2 - Exemplo da estratificação para a projeção de consumo de GN.

Fonte: própria, baseada em adaptação do CNAE (IBGE, 2003).

Este método combina informações sobre consumo de energia e planejamento urbano. Nos últimos níveis (quatro e cinco) o modelo exige a caracterização amostral de indústrias, comércio, serviços e residências, para um levantamento minucioso de dados físicos do imóvel, do consumo de outras fontes de energia e do número de equipamentos que podem ser convertidos ao gás natural. Porém o modelo prevê também a projeção de consumo indireta baseada nas características de uso e ocupação do solo expressas pela hipótese de que, quanto maior o número de domicílios, estabelecimentos comerciais/prestação de serviços e instalações industriais alocadas na célula em estudo, maior é a atratividade de implantação da rede canalizada de gás natural. Neste caso sugere-se a inserção pelo usuário de um peso externo que é multiplicado ao valor já digitado em função do número de unidades, para diferenciar os ramos de atividade que são mais propícios à utilização do gás natural ou que por outros motivos são mais atraentes para a concessionária.

Propõe-se que a utilização do método sempre tenha início no nível cinco que utiliza a verificação in loco de cada unidade, segundo amostragem. Neste caso, a entrada dessas características faz um "looping" dentro do programa, ou seja, se repete tantas vezes quantas forem as unidades amostrais digitadas, sempre relacionadas ao grau de estratificação anterior (o nível quatro). Caso não haja informações suficientes os graus iniciais também determinam o índice de atratividade, mas com menor precisão, já que não trabalham diretamente com projeção de consumo de energia.

Revista de Administração e Inovação, São Paulo, v. 10, n.2, p. 102-122, abr./jun. 2013. 
Desta forma o usuário do modelo deve sempre começar pelo nível da pesquisa in loco, trabalhando com informações sobre consumo de energia, equipamentos e características do setor e verificar se possui os dados questionados. Em caso negativo, deve passar para o nível imediatamente acima onde é exigido menor detalhamento dos dados e assim sucessivamente até chegar ao nível um onde basta informar para a área de estudo:

- O número de instalações industriais;

- O número de estabelecimentos comerciais e de prestação de serviços;

- O número de domicílios.

$\mathrm{O}$ número de unidades de cada segmento (domicílios e atividades econômicas) referente à célula de estudo, é somado de acordo com o tipo de uso do solo a que se refere, originando assim, quatro agrupamentos (residências, comércio, serviços e indústrias), visando sua utilização na próxima fase proposta nesta metodologia, que corresponde à aplicação do algoritmo, conforme será demonstrado em seguida.

\section{Sistema de Informações 4 - Indicadores da Obra civil (implantação dos dutos) (IOC)}

Considerando o desenvolvimento tecnológico da obra civil (representado pelo chamado "método não destrutivo", ABRATT, 2003) [4] e o papel da administração pública em obras de infraestrutura nos centros urbanos já consolidados (tendo como exemplo o Município de São Paulo), que vem facilitando a implantação de redes em cidades consolidadas, insere-se neste item parâmetros que envolvem as distâncias a percorrer dentro da área de estudo e entre ela e o último ponto já servido, bem como sua importância de ligação com outros bairros e municípios, exigindo maior agilidade no processo da obra. A função do sistema de informações que contem os indicadores da obra civil é a de representar valores associados ao custo da obra civil, como extensão dos dutos e seu diâmetro, assim como apontar diretrizes de interdição de vias de grande importância no distrito (tabela 5).

Optou-se por não associar valores numéricos às distâncias, considerando que erros grosseiros no detalhamento da obra civil possam ser cometidos e que a simples representação das distâncias já representa o custo da obra.

Outro ponto diferencial do modelo proposto neste trabalho é a inclusão do parâmetro "densidade construída por uso do solo" que aponta concentrações de domicílios e estabelecimentos produtivos considerando seu porte em área construída, favorecendo a interpretação de áreas verticalizadas ou com predominância de grandes instalações de atividade econômica o que indiretamente traduz a menor ou maior necessidade de ramificações das tubulações, com base na 
premissa quanto maior é a concentração de área construída residencial, maior é a ramificação necessária para conectar a rede aos edifícios e ao contrário, quanto maior a área construída industrial, menor é a necessidade de ramificar a rede, tornando em linhas gerais a implantação além de mais rápida, menos onerosa.

Vale ressaltar que para os três primeiros parâmetros da tabela 5, as faixas são consideradas em ordem inversa, ou seja, quanto menor à distância, maior o peso. Assim, distritos localizados na área já parcialmente servida por gás canalizado recebem índice 9, expressando a melhor condição de atratividade.

Tabela 5 - Sistema de Informações 4 - Indicadores da Obra Civil (OC)

\begin{tabular}{|c|c|c|c|c|}
\hline Parâmetros & Sigla & Unidade & Característica & Função \\
\hline $\begin{array}{c}\text { Distância do ponto a servir } \\
\text { ao último ponto já servido }\end{array}$ & $\mathrm{D}$ & $\mathrm{Km}$ & Não finito & $\begin{array}{c}\text { Determinante da } \\
\text { expansão física da rede }\end{array}$ \\
\hline $\begin{array}{c}\text { Extensão total das vias a } \\
\text { servir na área de análise }\end{array}$ & $\mathrm{E}$ & $\mathrm{Km}$ & Não Finito & $\begin{array}{c}\text { Determinante da } \\
\text { expansão física da rede }\end{array}$ \\
\hline $\begin{array}{c}\text { Incidência de vias de } \\
\text { grande tráfego }\end{array}$ & $\mathrm{T}$ & Adimensional & Não Finito & $\begin{array}{c}\text { Determinante da } \\
\text { expansão física da rede }\end{array}$ \\
\hline $\begin{array}{c}\text { Densidade Construída } \\
\text { (residencial, comercial, } \\
\text { serviços, industrial) }\end{array}$ & $\begin{array}{c}\text { DC res, DC } \\
\text { com, DC } \\
\text { serv, DC ind }\end{array}$ & $\mathrm{m}^{2} / \mathrm{km}^{2}$ & Não Finito & $\begin{array}{c}\text { Determinante da } \\
\text { expansão física da rede }\end{array}$ \\
\hline
\end{tabular}

Fonte: própria, 2007.

Conforme descrito na metodologia, todos os valores coletados nos quatro sistemas de informações são unificados à mesma unidade (porcentagem) e divididos em cinco faixas de atratividades que são convertidas na escala de hierarquização de 1 a 9. Feito isso, os pesos atribuídos são submetidos ao cálculo do "Índice de Atratividade", cujo algoritmo baseado na soma simples dos pesos para cada célula de estudo, é resumido na tabela 6.

Tabela 6 - Resumo do algoritmo para o Índice de Atratividade

\begin{tabular}{|c|}
\hline Índices de Atratividade por Sistemas de Informação \\
\hline $\mathrm{IQV}=(\mathrm{IEX}+\mathrm{IDH}+\mathrm{AAA}+\mathrm{AEC}+\mathrm{AIP}) / \mathrm{n}$ \\
\hline $\mathrm{IPU}=($ Usres+Uscom+Usserv+Usind+Z+DU+TU+Lires+Liserv $) / \mathrm{n}$ \\
\hline $\mathrm{IPC}=(\mathrm{DD}+\mathrm{RF}+$ Eres+Ecom+Eserv+Eind $) / \mathrm{n}$ \\
\hline $\mathrm{IOC}=(\mathrm{D}+\mathrm{E}+\mathrm{T}+\mathrm{Dcres}+\mathrm{Dccom}+\mathrm{Dcserv}+\mathrm{Dcind}) / \mathrm{n}$ \\
\hline Índice de Atratividade Geral \\
\hline IGeral= $(\mathrm{IQV}+\mathrm{IPU}+\mathrm{IPC}+\mathrm{IOC}) / \mathrm{n}$ \\
\hline
\end{tabular}

Nota1: "n" representa o número de parâmetros efetivamente utilizados.

Nota 2: Siglas definidas nas tabelas 2, 3,4 e 5. Fonte: própria, 2007.

Revista de Administração e Inovação, São Paulo, v. 10, n.2, p. 102-122, abr./jun. 2013. 


\section{ESTUDO DE CASO}

Segundo as "Recomendações sobre a Política para o GN" (IE, 2004), a escolha de São Paulo (capital paulista) como uma "Cidade Toda-Gás", serve para efeito de demonstração da completa utilização do gás natural em todas as suas aplicações. No caso deste trabalho, essa escolha tem respaldo:

- $\quad \mathrm{Na}$ complexidade do município paulistano, fonte inesgotável de debates e conclusões sociais, econômicas e técnicas para expansão de infra-estruturas;

- No processo da obra civil que vem evoluindo com o uso do método não destrutivo de abertura de valas, a trenchless technology [4] (ISTT, 2008), diminuindo o transtorno oriundo da interdição e recapeamento das vias de tráfego e com isso, barateando sua execução, principalmente em áreas urbanas já consolidadadas, como é o caso da cidade de São Paulo.

Como limitação espacial dentro da Cidade de São Paulo, usaremos neste estudo, a divisão em 96 distritos em conformidade com as informações disponibilizadas pela Secretaria Municipal de Planejamento Urbano e pela Empresa Metropolitana de Planejamento (SÃO PAULO, 2002; 2006; EMPLASA, 2008).

Para a utilização do modelo neste trabalho, foram consideradas as seguintes simplificações:

- C Cálculo do índice de Atratividade, usando o agrupamento "Geral” (sem a divisão em sistemas de informação) e seu respectivo ranking;

- $\quad$ Célula de Estudo: distrito;

- Projeção de Consumo de Gás Natural (sistema de informações 3): usando estratificação nível um para todos os usos (residências, comércio, serviço e indústrias);

- $\quad$ Peso Extra para ressaltar segmentos mais propícios ao uso do gás natural=1,0 para todos os usos.

- $\quad$ Aplicação do algoritmo (conforme as somas definidas na tabela 6).

Para estudo de caso foram selecionados dez distritos da zona leste da capital paulista com as mais diferentes características. Alguns deles já possuem a rede de gás natural de forma pontual, porém todos podem ser considerados no estágio de expansão, já que nenhum deles está completamente servido.

Em cada um dos sistemas de informação, é atribuída a escala AHP, que destaca os melhores e piores parâmetros na atratividade para o gás natural, conforme a tabela 7 .

Revista de Administração e Inovação, São Paulo, v. 10, n.2, p.102-122, abr./jun. 2013. 
Tabela 7 - Atribuição de pesos aos Sistemas de Informações

\begin{tabular}{|c|c|c|c|c|c|c|c|c|c|c|c|}
\hline Sistema & Parâmetros & $\begin{array}{l}\text { Água } \\
\text { Rasa }\end{array}$ & Aricanduva & Cangaíba & $\begin{array}{c}\text { Ermelino } \\
\text { Matarazzo }\end{array}$ & Itaquera & Penha & $\begin{array}{c}\text { São } \\
\text { Miguel }\end{array}$ & Tatuapé & $\begin{array}{c}\text { Vila } \\
\text { Prudente }\end{array}$ & $\begin{array}{c}\text { Vila } \\
\text { Formosa }\end{array}$ \\
\hline \multirow{5}{*}{1} & IEX & 9 & 9 & 5 & 5 & 3 & 7 & 3 & 9 & 7 & 9 \\
\hline & IDH & 7 & 9 & 3 & 3 & 3 & 5 & 3 & 5 & 5 & 7 \\
\hline & AAA & 9 & 9 & 7 & 7 & 7 & 7 & 9 & 9 & 9 & 9 \\
\hline & ACE & 9 & 9 & 9 & 7 & 7 & 9 & 9 & 9 & 9 & 9 \\
\hline & AIP & 7 & 9 & 7 & 5 & 7 & 9 & 9 & 9 & 9 & 7 \\
\hline \multirow{9}{*}{2} & US res & 5 & 9 & 9 & 5 & 7 & 5 & 9 & 5 & 5 & 9 \\
\hline & US com & 3 & 1 & 3 & 3 & 1 & 7 & 1 & 7 & 3 & 3 \\
\hline & US serv & 3 & 3 & 1 & 5 & 1 & 9 & 1 & 9 & 3 & 1 \\
\hline & US ind & 5 & 1 & 1 & 7 & 5 & 1 & 1 & 1 & 5 & 1 \\
\hline & $\mathrm{Z}$ & 7 & 7 & 5 & 7 & 7 & 7 & 7 & 7 & 7 & 7 \\
\hline & $\mathrm{DU}$ & 9 & 9 & 9 & 9 & 9 & 5 & 9 & 5 & 9 & 9 \\
\hline & TU & 9 & 9 & 9 & 9 & 9 & 9 & 9 & 9 & 9 & 9 \\
\hline & LI res & 1 & 9 & 1 & 1 & 7 & 5 & 1 & 9 & 9 & 3 \\
\hline & LI serv & 5 & 9 & 1 & 1 & 5 & 9 & 1 & 9 & 9 & 1 \\
\hline \multirow{6}{*}{3} & DD & 5 & 7 & 3 & 5 & 7 & 5 & 5 & 3 & 3 & 5 \\
\hline & RF & 5 & 7 & 1 & 1 & 1 & 1 & 1 & 5 & 1 & 3 \\
\hline & E res & 3 & 3 & 5 & 3 & 7 & 5 & 3 & 3 & 3 & 3 \\
\hline & E com & 1 & 5 & 1 & 3 & 9 & 9 & 9 & 7 & 9 & 5 \\
\hline & E serv & 3 & 5 & 3 & 3 & 5 & 9 & 3 & 7 & 7 & 5 \\
\hline & E ind & 3 & 3 & 1 & 1 & 3 & 5 & 1 & 5 & 5 & 3 \\
\hline \multirow{7}{*}{4} & $\mathrm{D}$ & 1 & 7 & 5 & 5 & 3 & 3 & 7 & 9 & 5 & 3 \\
\hline & $\mathrm{E}$ & 3 & 7 & 9 & 5 & 7 & 1 & 5 & 7 & 7 & 5 \\
\hline & $\mathrm{T}$ & 3 & 3 & 5 & 3 & 5 & 1 & 3 & 1 & 1 & 3 \\
\hline & DC res & 9 & 5 & 3 & 3 & 3 & 7 & 5 & 9 & 7 & 9 \\
\hline & DC com & 9 & 5 & 1 & 3 & 3 & 7 & 7 & 5 & 5 & 9 \\
\hline & DC serv & 9 & 5 & 1 & 3 & 3 & 7 & 7 & 5 & 5 & 9 \\
\hline & DC ind & 7 & 5 & 1 & 3 & 1 & 3 & 1 & 5 & 5 & 1 \\
\hline
\end{tabular}

Fonte: SEADE, 2009; EMPLASA, 2008; SÃO PAULO, 2006 com base em SAATY, 2006.

A opção de avaliação é o ranking geral, usando no banco de dados 3, o nível quatro de projeção de consumo (o mais detalhado ainda trabalhando apenas com número de unidades) visando simplificar a demonstração. A figura 3 mostra os distritos analisados. 


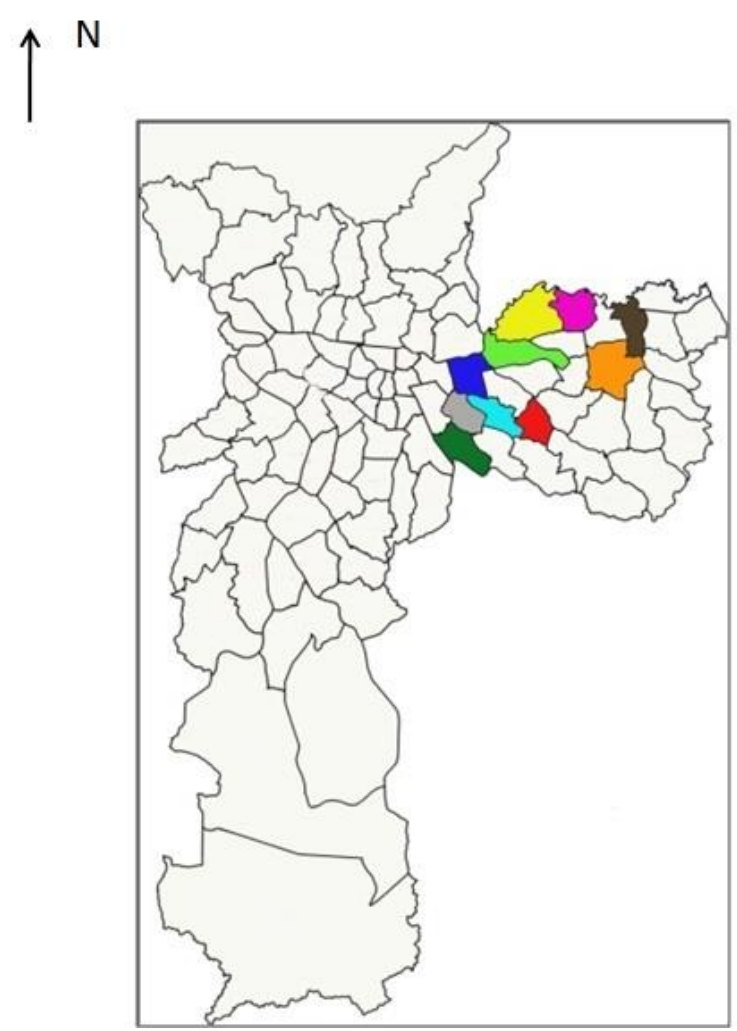

Figura 3 - Os distritos no mapa da Cidade de São Paulo. Fonte: SEMPLA, 2006.

O resultado demonstrado na tabela 8 se deve a vários fatores urbanos. Os primeiros colocados são distritos com maior verticalização residencial, maior liberdade de zoneamento, estão mais próximos à áreas já servidas e é claro, tem maior projeção de consumo de GN. Os demais concentram menor renda, uso residencial horizontal e pouca concentração comercial, serviços e industrial. Os últimos na classificação além das características do grupo intermediário, estão em área com restrições a expansão e portanto, de pequeno desenvolvimento urbano. 


\begin{tabular}{clcc}
\hline Legenda & \multicolumn{1}{c}{ Distrito } & Igeral & Ranking \\
\hline \hline & Água Rasa & 5,5 & $5^{\circ}$ \\
\hline & Aricanduva & 6,2 & $2^{\circ}$ \\
\hline Cangaíba & 4,1 & $10^{\circ}$ \\
\hline \hline Ermelino Matarazzo & 4,2 & $9^{\circ}$ \\
\hline Itaquera & 5,0 & $7^{\circ}$ \\
\hline Penha & 5,8 & $4^{\circ}$ \\
\hline & São Miguel & 4,8 & $8^{\circ}$ \\
\hline & Tatuapé & 6,4 & $1^{\circ}$ \\
\hline & Vila Formosa & 6,0 & $3^{\circ}$ \\
\hline & Vila Prudente & 5,4 & $6^{\circ}$ \\
\hline
\end{tabular}

\section{Tabela 8 - O Ranking de Atratividade à Rede de GN.}

Fonte: própria, baseada em Saaty, 2006.

A proposição metodológica sobre o algoritmo demonstrado à tabela 6 é validada já que sua comparação com o método de análise hierárquica que trabalha com a avaliação de parâmetros "par a par” (Saaty, 2006), apresenta a mesma ordem dos distritos para o ranking de atratividade à rede de gás natural.

O resultado também concorda com o plano de expansão da concessionária (COMGÁS, 2007/08), evidenciando novamente que a seleção dos parâmetros bem como a atribuição dos pesos e do algoritmo resulta em um ranking que traduz a realidade de mercado.

Os primeiros colocados são distritos com maior desenvolvimento do mercado imobiliário, maior liberdade de zoneamento, estão mais próximos à áreas já servidas e é claro, têm maior projeção de consumo de GN, principalmente no uso residencial vertical (com destaque para os distritos Tatuapé, Aricanduva, Penha, Vila Prudente e Água Rasa). Os demais concentram menor renda, uso residencial horizontal e pouca concentração comercial, de serviços e indústria (Vila Formosa, Ermelino Matarazzo, Itaquera e São Miguel Paulista). O último na classificação (Cangaíba) além das características do grupo intermediário está em área com restrições ambientais à expansão e, portanto, com menor dinâmica urbana.

A proximidade na primeira casa decimal entre alguns distritos pode ser mais bem avaliada, levando em conta a "localização ótima" através da identificação dos pontos cardeais de cada célula de estudo, conforme a direção que se pretenda dar à expansão da rede (decisão da concessionária), ou pela análise dos rankings parciais que o modelo oferece divididos nos quatro sistemas de informações.

Revista de Administração e Inovação, São Paulo, v. 10, n.2, p. 102-122, abr./jun. 2013. 


\section{CONCLUSÕES}

Como avanço específicos esperados através da metodologia proposta elenca-se:

- A avaliação da influência conjunta de parâmetros sociais, técnicos e econômicos na tomada de decisão para investimentos em infra-estrutura nas empresas privadas;

- O desenvolvimento de um modelo para prospecção de mercados de gás natural de fácil utilização com o diferencial de ser baseado no conceito de dinâmica urbana;

- A utilização do modelo como instrumento de referência para a otimização de estudos sobre a expansão da rede de distribuição do GN, envolvendo aspectos usuais como custos e demanda e outros, como o planejamento urbano e a qualidade de vida, abordando não somente a ótica das concessionárias como também o enfoque das prefeituras, na análise da inserção de redes de serviços públicos e privados;

- A organização da modelagem de indicadores que possam servir como banco de dados para a implantação de outros serviços essenciais às atividades sócio-econômica das cidades;

- A observação quanto à inclusão em Planos Diretores de procedimentos sustentáveis para a implantação do serviço de gás natural, em áreas de urbanização já consolidada, reforçando o uso de métodos construtivos não destrutivos.

A metodologia propicia a detecção de diferenças internas às tendências globais da cidade, através da síntese de parâmetros variáveis. A possibilidade de abordagem das variáveis em diferentes unidades territoriais (também promove leituras diversificadas da cidade, quanto maior a agregação, uma maior homogeneização ocorre, escondendo realidades "locais". Desta forma, a unidade territorial de análise utilizada deve se adequar aos objetivos da pesquisa, ou seja, ao nível de detalhes que se deseja e que é possível chegar. Assim, é interessante sempre que possível usar menores células de estudo e aumentar a precisão dos rankings.

A verificação de cada célula de estudo (nesse caso o distrito), sempre deve ser relacionada com o levantamento análogo de seu entorno, tendo como base sua distância euclidiana da área já servida. Esta observação é de suma importância para os distritos da periferia, que podem mostrar no estudo numérico, inadequação à expansão da rede, mas que na análise conjunta dos distritos ao redor, com melhores índices de atratividade, podem vir a oferecer em médio prazo novos eixos de consumo.

A criação de um mercado residencial e comercial baseado na introdução gradativa do gás natural nos usos cotidianos pode acabar por induzir uma clientela que viabilize a introdução de canalização de distribuição nas grandes cidades brasileiras. Porém, para que haja maior potencial de

Revista de Administração e Inovação, São Paulo, v. 10, n.2, p.102-122, abr./jun. 2013. 
expansão do serviço em rede, faz-se necessária também a intensificação da relação entre concessionárias, projetistas de instalações de gás e toda a construção civil, o desenvolvimento de equipamentos para diversos fins que possam utilizar o GN, além do auxílio de órgãos públicos na implementação da infra-estrutura e na divulgação do uso do gás natural enquanto agente de desenvolvimento urbano.

Desta forma, o modelo pretende desempenhar papel auxiliar nesse processo, identificando as possibilidades de em um futuro próximo, se utilizar o gás natural canalizado não somente em bairros próximos aos grandes centros urbanos de grande desenvolvimento imobiliário e maior concentração de renda, mas também, em áreas periféricas, com a mesma intensidade e facilidade com que atualmente utiliza-se, por exemplo, a energia elétrica, gerando assim, novos empregos vinculados à construção civil, tanto no âmbito da inserção dos dutos subterrâneos, quanto na adaptação das instalações internas das edificações, no desenvolvimento da nossa indústria e pesquisa e por fim, maior qualidade de vida para a população, independentemente de sua condição social.

\section{AGRADECIMENTOS}

Os autores agradecem o apoio da Agência Nacional do Petróleo - ANP, da Financiadora de Estudos e Projetos - FINEP e do Ministério da Ciência e Tecnologia - MCT por meio do Programa de Recursos Humanos da ANP para o Setor Petróleo e Gás - PRH-ANP/MCT e também o apoio da Fundação de Amparo à Pesquisa do Estado de São Paulo - FAPESP no Projeto 03/06441-7: Novos Instrumentos de Planejamento Energético Regional Visando o Desenvolvimento Sustentável.

\section{REFERÊNCIAS}

ABEGÁS - Associação Brasileira do Gás Natural. O mercado de gás natural no Brasil em 2008. In: Revista Gas Net, março, 2008.

ABRATT - Associação Brasileira de Tecnologia não Destrutiva. Métodos não destrutivos para dutos subterrâneos. In: Revista O Empreiteiro, maio de 2003. p 21-25.

Revista de Administração e Inovação, São Paulo, v. 10, n.2, p. 102-122, abr./jun. 2013. 
BNDES - Banco Nacional de Desenvolvimento Econômico e Social. Setor de Petróleo e Gás: Perfil dos Investimentos. Brasília, BNDES, 2006.

COMGÁS - Companhia de Gás de São Paulo. Mapa da área Coberta pela Rede. São Paulo, COMGÁS, 2007/08.

EMBRAESP - Empresa Brasileira de Estudos de Patrimônio. Relatório anual sobre número de lançamentos imobiliários por região. São Paulo, Embraesp, 2008.

EMPLASA - Empresa Metropolitana de Planejamento. O perfil institucional da Região Metropolitana de São Paulo. São Paulo, Emplasa, 2008.

Forrester J. W. Urban Dynamics. Cambridge, M.I.T. Press, 1969.

Gas Brasil. Newsletter Semanal, Rio de Janeiro, out, 2008.

Heideier, R. B.; Ueocka, M. Z; Udaeta, M. E. M. Análise e Avaliação do Mercado Reprimido de energia no contexto do desenvolvimento limpo na região Administrativa de Araçatuba. In: Revista de Administração Pública, v. 43, p. 875-896, 2008.

IBGE - Instituto Brasileiro de Geografia e Estatística. Cadastro Nacional das Atividades Econômicas (CNAE). Rio de Janeiro, IBGE, 2003.

IE - Instituto de Engenharia de São Paulo. Recomendações sobre a política para o gás natural. São Paulo, IE, 2004.

International Society for Trenchless Technology - ISTT. Trenchless techniques, Londres, ISTT, 2008.

Massara, V.M. O Perfil da Infra-Estrutura no Município de São Paulo e sua relação com as transformações de uso do solo: o Centro Expandido e a região de São Miguel Paulista. São Paulo, Dissertação (Mestrado em Engenharia Civil), Escola Politécnica da Universidade de São Paulo, 2002.

Massara, V.M. A Dinâmica Urbana na Otimização da Infra-Estrutura para o Gás Natural. São Paulo, Tese (Doutorado em Energia), Instituto de Eletrotécnica e Energia da Universidade de São Paulo, 2007.

Ministério das Cidades. Plano Diretor Participativo - Guia para a Elaboração pelos Municípios e Cidadãos. Brasília, 2006.

Saaty, T. The Analytic Hierarchy Process: Planning, Priority Setting, Resource Allocation. Londres, McGraw-Hill, Londres. 1980.

Saaty, T. Manual de uso do Programa Computacional Decision Lens. Londres, 2006.

São Paulo (cidade) - Secretaria Municipal de Planejamento Urbano. Dinâmica Urbana. São Paulo, Sempla, 2006.

São Paulo (cidade) - Secretaria Municipal de Planejamento Urbano. Plano Diretor estratégico do Município de São Paulo 2002-2012. São Paulo, Sempla, 2002.

Revista de Administração e Inovação, São Paulo, v. 10, n.2, p.102-122, abr./jun. 2013. 
SEADE - Fundação Sistema Estadual de Análise de Dados. Pesquisa Municipal Unificada, São Paulo, Seade, 2009.

Shively, B. Ferrare, J. Understanding today's natural gas business. San Francisco, Energy Dynamics LLC, 2004.

Udaeta, M.E.M. Planejamento Integrado de Recursos Energéticos - PIR para o Setor Elétrico (Pensando o Desenvolvimento Sustentável). São Paulo, Tese (Doutorado em Engenharia), Escola Politécnica da Universidade de São Paulo, 1997.

Udaeta, M. E. M.; Burani, G. F.; Fagá, M. T.W.; Rigolin, P. H.C. Pesquisa Tendências Tecnológicas e Demanda Profissional do Setor Petróleo e Gás. São Paulo, Programa de Recursos Humanos Nº 4 da Agência Nacional do Petróleo, 2004.

Udaeta, M.E.M.; Grimoni, J.A.B.; Burani, G.F.; Rigolin, P.H.C.; Massara, V.M. Fundamentos e Introdução à Cadeia Produtiva do Gás Natural. São Paulo, EDUSP/FAPESP, 2010. 262p.

\section{Notas}

[1] As redes de distribuição transportam volumes menores de gás natural a menores pressões, com tubulações de diâmetros menores que na rede de transporte. É esta rede que recebe o gás dos gasodutos e o leva até as indústrias e aos centros urbanos e por fim, até o usuário final, através de ramificações menores de modo a atender os bairros ou distritos.

[2] O uso industrial sozinho, por seu caráter apenas de atividade econômica (e que em geral pode ter instalações próprias), justifica o uso da rede de gás natural mesmo que haja déficits em outras redes ou serviços.

[3] O Plano Diretor é uma Lei Municipal que organiza o crescimento e funcionamento da cidade. Ele diz quais os objetivos a serem alcançados, em cada área da cidade e, para viabilizá-los, identifica instrumentos urbanísticos e ações estratégicas que devem ser implementadas. Orienta as prioridades de investimentos da cidade, ou seja, indica as obras estruturais a realizar. Tradicionalmente, estas diretrizes incluem normas para o adensamento, expansão territorial, definição de zonas de uso do solo e redes de infra-estrutura. É também um instrumento global e estratégico da política de desenvolvimento urbano, determinante para todos os agentes públicos e privados que atuam no Município. (MINISTÉRIO DAS CIDADES, 2006).

Revista de Administração e Inovação, São Paulo, v. 10, n.2, p. 102-122, abr./jun. 2013. 
[4] Os chamados Métodos Não Destrutivos utilizam máquinas especiais que perfuram o subsolo horizontalmente, entre dois poços de acesso, por onde serão passadas as tubulações. Desta forma, não é necessário rasgar toda a extensão do piso por sob o qual passará a instalação. Esse método é extremamente útil quando da travessia de vias de grande tráfego, uma vez que o trânsito de veículos não será prejudicado pelas obras. A execução por este processo também evita a reposição do pavimento por abertura de valas, reposição esta que nem sempre é igual à situação original do pavimento. No Brasil, sua aplicabilidade é destinada à execução de serviços em tubulações de polietileno e aço para trabalhos até 2 metros de profundidade que podem ser: transmissão e distribuição de energia elétrica; telecomunicações; transmissão e distribuição de televisão via cabo; distribuição de derivados de petróleo e gás; travessia de avenidas, rodovias, rios e ferrovias; sistemas de drenagem de subsolo; instalações industriais; substituição de tubulações, etc. O custo direto em muitos casos já é equivalente ao método com abertura de valas contínuas, mas as vantagens são enormes: precisão na execução da obra; redução de prazos; não interrupção do trânsito na área de trabalho e grande redução do custo social (ABRATT, 2003).

\title{
PROPOSAL OF METHODOLOGY FOR ANALYSIS OF NETWORK EXPANSION OF NATURAL GAS IN BRAZILIAN CITIES USING URBAN INDICATORS
}

\begin{abstract}
This paper presents a methodology for determining areas attractive for the deployment of natural gas network under the approach of urban development. The point considered innovative in this proposal is based on the inclusion of parameters removed of master plans besides to the known cost and facilities technology. Thus, the modeling includes the dynamics of cities located in Brazilian metropolitan areas, in constant transformation of land use by the intensification of real estate market and even zoning, making sub-areas vectors used for energy consumers. In conclusion, presents the test of the proposition for 10 districts of east of the state capital, demonstrating the important role that urban dynamics must be considered in the decision process for deploying and expansion of network infrastructure.
\end{abstract}

Key-words: Innovation; Urban development; Infrastructure.

Data do recebimento do artigo: 25/11/2012

Data do aceite de publicação: 02/04/2013

Revista de Administração e Inovação, São Paulo, v. 10, n.2, p.102-122, abr./jun. 2013. 